\title{
Impact behavior of reinforced concrete slabs subjected to rock fall loading
}

\author{
K. Schellenberg, S. Ghadimi Khasraghy \& T. Vogel \\ ETH Zurich, Institute of Structural Engineering, Zurich, Switzerland
}

\begin{abstract}
This research aims at providing a better understanding of the dynamic behavior of rock fall protection galleries. To improve the prediction accuracy for the impact load capacity, analytical, numerical and experimental works have been carried out.

According to a survey of galleries in Switzerland, the relevant geometries for the tests were chosen in a scale of about 1:2. Concrete slabs with lateral dimensions of $3.5 \times 4.5 \mathrm{~m}$ and a thickness of $0.35 \mathrm{~m}$ were subjected to falling weight impacts with increasing falling height. Measuring the reaction forces as well as strains in the reinforcement and on the concrete surface, the required data to validate an analytical model was gained.

In this contribution, the observed crack patterns of the slabs due to the impacts are discussed. The impact load and the strains can be predicted using an analytical model consisting of three masses and three nonlinear springs. As a comparison, the values given by the design guidelines of Switzerland and Japan are illustrated, too.
\end{abstract}

Keywords: falling weight impact, rock fall galleries, crack patterns, analytical model, experimental results.

\section{Introduction}

The risk of rock fall events is increasing due to the climate changes and deicing of the permafrost. On the other hand, the risk acceptance decreases according to the quality of life in our society. Considering the population growth and the high mobility requirements into and through alpine regions, professionals need to improve the protection against rock fall hazards. 
Rock fall galleries are an efficient measure to protect roads and railways, especially when the endangered area is relatively small and well defined. A survey of existing rock fall galleries in Switzerland has shown that most of them consist of reinforced concrete slabs and are covered by a cushion layer. Usually, granular soil from the surroundings is used as cushion layer.

Protection galleries typically span $9 \mathrm{~m}$ with a slab thickness of approximately $0.70 \mathrm{~m}$. The back side of the gallery is rigidly connected with the retaining wall; the valley side is supported on columns (see Figure 1) with a typical spacing of 7 meters. The impact load capacity of the existing galleries is of great interest mainly to decide on the necessity of strengthening. The Swiss design guideline for rock fall galleries was published in 1998 [1]. Older galleries are mostly designed by local engineers based on oversimplifications.

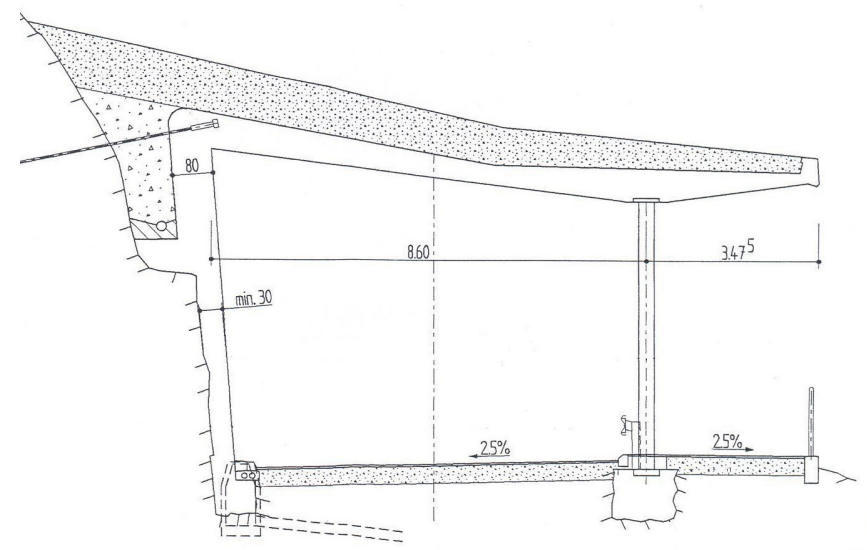

Figure 1: $\quad$ Typical Swiss rock fall gallery, Axenstrasse Süd, Canton of Uri.

\section{Experimental research}

Reinforced concrete slabs with lateral dimensions of $3.5 \times 4.5 \mathrm{~m}$ were subjected to impact by a boulder of $800 \mathrm{~kg}$ and $4000 \mathrm{~kg}$, respectively. The falling height was increased after every impact until the slab failed. The slabs had one line and two single supports (Figure 2). To avoid a shear failure of these supports two steel beams welded to an elbow were cast-in over the supports. The complete test series with different slab thicknesses, reinforcement layouts and different cushion layers led to a total of 38 impact tests. The test setup and program are described more detailed in [2]. The tests were carried out in April 2007 together with the Swiss Federal Institute for Forest, Snow and Landscape Research (WSL) and Geobrugg Protection Systems in their common outdoor testing area.

This paper is focused on nine impacts tests (Table 1) carried out on two identical slabs, where: (i) slab thickness was $0.35 \mathrm{~m}$, (ii) reinforcing bars of 22 $\mathrm{mm}$ diameter were placed with a spacing of $0.155 \mathrm{~m}$ in both directions and (iii) the slab was covered by a $0.4 \mathrm{~m}$ thick gravel layer. The impacts B1 to B7 and D1 to D2 affect the slabs B and D respectively. 


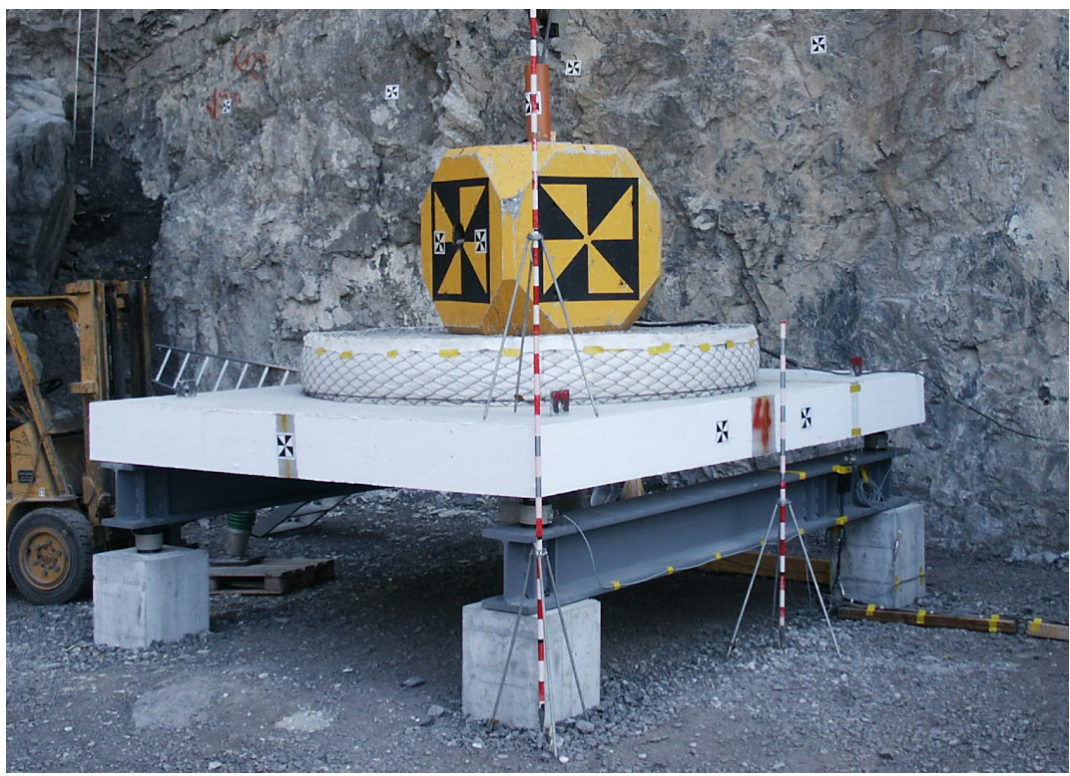

Figure 2: $\quad$ Test setup with gravel cushion and $4000 \mathrm{~kg}$ boulder.

Table 1: Overview of the test program and results.

\begin{tabular}{|c|c|c|c|c|c|c|c|c|c|c|c|}
\hline \multicolumn{3}{|c|}{ Impact } & B1 & B2 & B3 & B4 & B5 & B6 & B7 & D1 & D2 \\
\hline \multicolumn{2}{|c|}{ Boulder mass } & {$[\mathrm{kg}]$} & 800 & 800 & 800 & 800 & 800 & 4000 & 4000 & 4000 & 4000 \\
\hline \multicolumn{2}{|c|}{ Falling height } & {$[\mathrm{m}]$} & 5 & 7.5 & 10 & 12.5 & 15 & 2 & 5 & 2 & 5 \\
\hline \multicolumn{2}{|c|}{ Gravel $M_{E}$-value } & {$[\mathrm{GPa}]$} & 48 & 52 & 47 & 56 & 54 & 48 & 47 & 56 & 52 \\
\hline \multicolumn{2}{|c|}{ Impact energy } & {$[\mathrm{kJ}]$} & 39 & 59 & 78 & 98 & 118 & 79 & 197 & 79 & 197 \\
\hline \multicolumn{2}{|c|}{ Reaction force } & [kN] & 1205 & 1592 & 1531 & 1845 & 1915 & 1731 & 2547 & 1869 & 2574 \\
\hline \multirow{6}{*}{ Strain } & $\mathrm{RB}_{1}$ & {$[\% 0]$} & 1.18 & 1.19 & 1.59 & 1.80 & 1.90 & 1.46 & 2.44 & 2.23 & $\mathrm{~N}$ \\
\hline & $\mathrm{RB}_{1, \mathrm{res}}$ & {$[\%$} & 0.2 & 0.0 & 0.0 & 0.0 & 0.0 & 0.0 & 0.1 & 0.3 & $\mathrm{~N}$ \\
\hline & $\mathrm{RB}_{2}$ & [\%o $]$ & 1.2 & 1.53 & 1.66 & 2.05 & 2.17 & 2.12 & $\mathrm{~N}$ & 2.12 & 3.33 \\
\hline & $\mathrm{RB}_{2 \text {,res }}$ & {$[\% 0]$} & 0.18 & 0.11 & 0.11 & 0.12 & 0.08 & 0.07 & $\mathrm{~N}$ & 0.32 & 0.0 \\
\hline & $\mathrm{CS}_{1}$ & [\%o] & -0.35 & -0.43 & -0.56 & -0.71 & -0.84 & -0.7 & -1.15 & -0.63 & -1.11 \\
\hline & $\mathrm{CS}_{2}$ & [\%o] & -0.44 & -0.51 & -0.6 & -0.77 & -0.89 & -0.74 & $\mathrm{~N}$ & -0.64 & -1.59 \\
\hline
\end{tabular}

Before every impact the gravel layer was loosened and pre-compacted to a $M_{E}$-value of approximately $50 \mathrm{GPa}$ insuring comparable conditions for all tests. The compaction measured by a Dynamic Light Drop-Weight Tester [3] is shown in Table 1.

These tests correspond to a scale of $1: 2$ and provide the required data to validate analytical models. Within the concrete slabs strains are measured in the reinforcing bar (RB) as well as on the concrete surface (CS) at the center of the slab. All strains as well as the reaction forces (RF) at the supports are measured with a sampling rate of $3200 \mathrm{~Hz}$. 


\section{Results}

As test results, the maximum values of the measurements (Table 1) and the crack patterns (Figure 3) are introduced in this section. The load time histories are shown later in the next section.

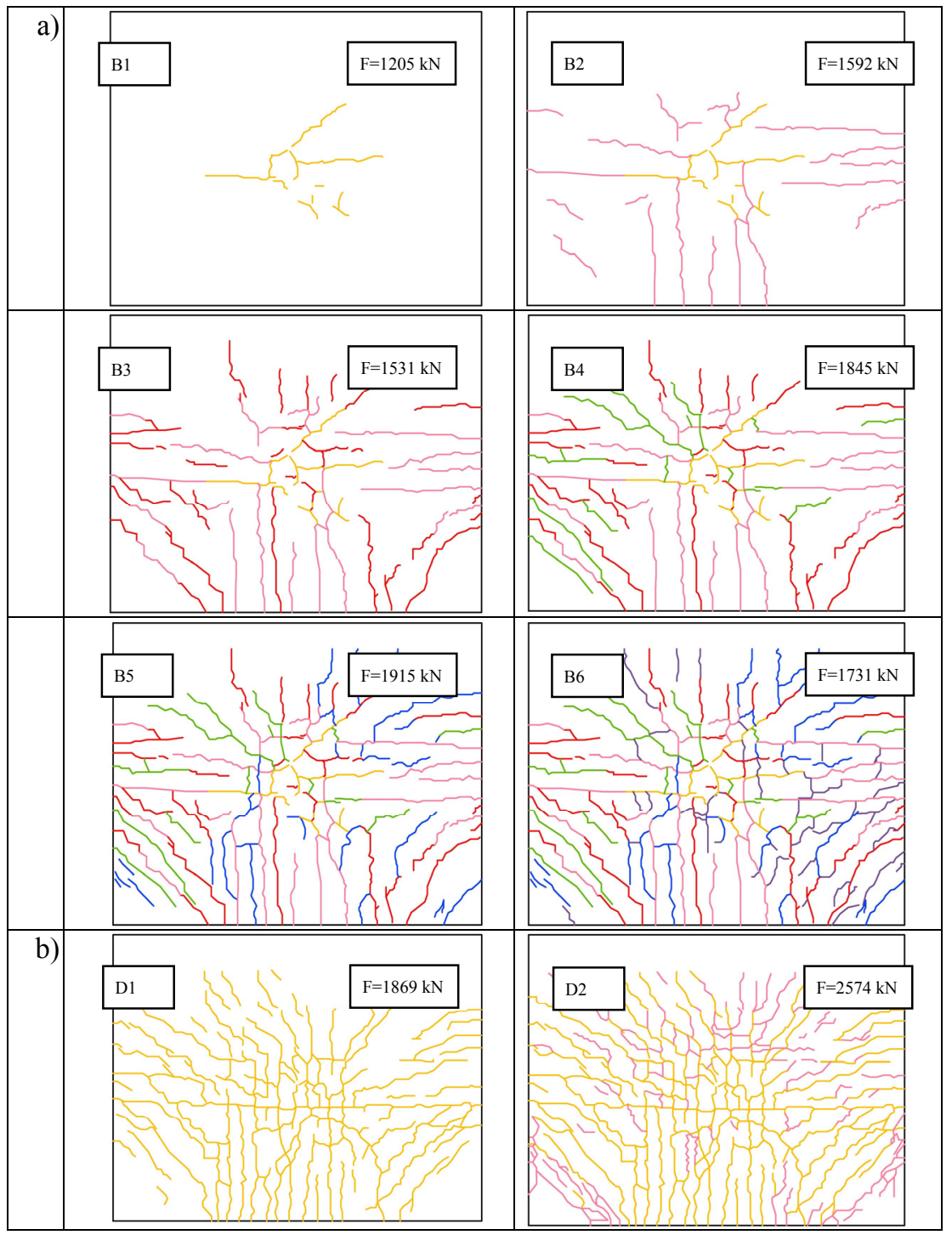

Figure 3: Slab crack patterns a) B1 to B6, and b) D1 to D2. 
The maximum reaction forces RF show an increase with higher impact energy. Only the maximum reaction force during impact B3 is lower compared to the previous impact B2 as well as compared to B6, which has the same kinetic energy.

The strains at the center of the slab are smaller in the direction of the first reinforcement layer $\left(\mathrm{RB}_{1}\right)$, which is placed along the short span. The residual strains (e.g. $\mathrm{RB}_{2, \text { res }}$ ) after every impact are not necessarily plastic deformations. They can be induced by cracks that are not completely closed. For strain $\mathrm{RB}_{1}$ only after impact B1 there is a residual strain. The strains at the upper concrete surface (CS) show the amount of compression, in the direction of the corresponding rebar layer. For an elastic slab reaction they correspond to the tensile strains at the soffit, where the crack patterns are shown. In Figure 3 the line supported sides are depicted at the top edges.

In impact B1 few local cracks were formed directly under the impact zone. As the impact energy increased, the flexural cracks developed to larger cracks and additional shear cracks appeared at supports. No flexural cracks were formed in the sections strengthened by the cast-in steel beams. Last two impacts on slab B led to widening and branching of the existing cracks and almost no new ones were formed. In impact B7 the slab failed by shear failure close to its supports.

\section{Evaluation}

The decrease of the maximum reaction force in impact B3 indicates the influence of the stiffness reduction due to cracking. Comparing impact B6 and D1 the influence of damage during previous impacts can be observed. Both impacts are identical; however, D1 produced more flexural cracks in the larger span and less shear cracks at the supports.

Figure 4 shows the average spacing of flexural cracks versus the impact energy and the cumulative energy for the impacts B2 to B6 and D1 to D2, respectively. Crack spacing in two zones are evaluated: Zone (1) is in the longer span of the slab and Zone (2) is the shorter span. As there were no flexural

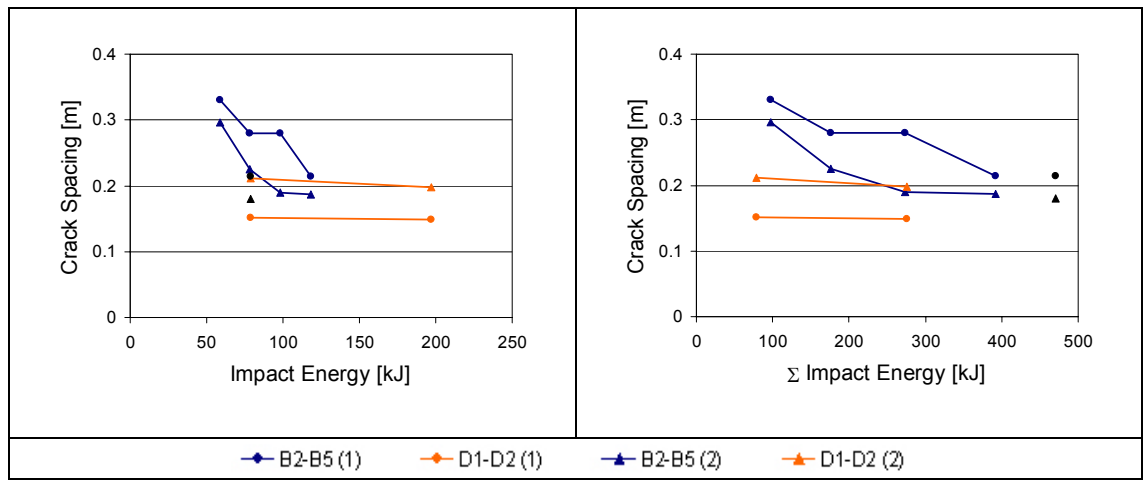

Figure 4: $\quad$ Crack spacing for impacts B2-B6 and D1-D2. 
cracks during impact $\mathrm{B} 1$, the curves start with impact $\mathrm{B} 2$. The impact energy of B6 is less than the one of B5, so the curves have been discontinued and the data is shown as single points.

The crack spacing decreases with increasing impact load until a minimum spacing is reached. There were almost no new cracks formed during the last two impacts of series B (B6 and B7), so the increase in the impact loads beyond B5 has only widened the existing cracks.

The range of crack spacing for these slab sections using the tension chord model described in [4] amounts between 100 and $200 \mathrm{~mm}$.

The dynamic process during rock fall impact on a protection gallery includes not only separate geotechnical and structural dynamic aspects, but also combined soil-structure interaction.

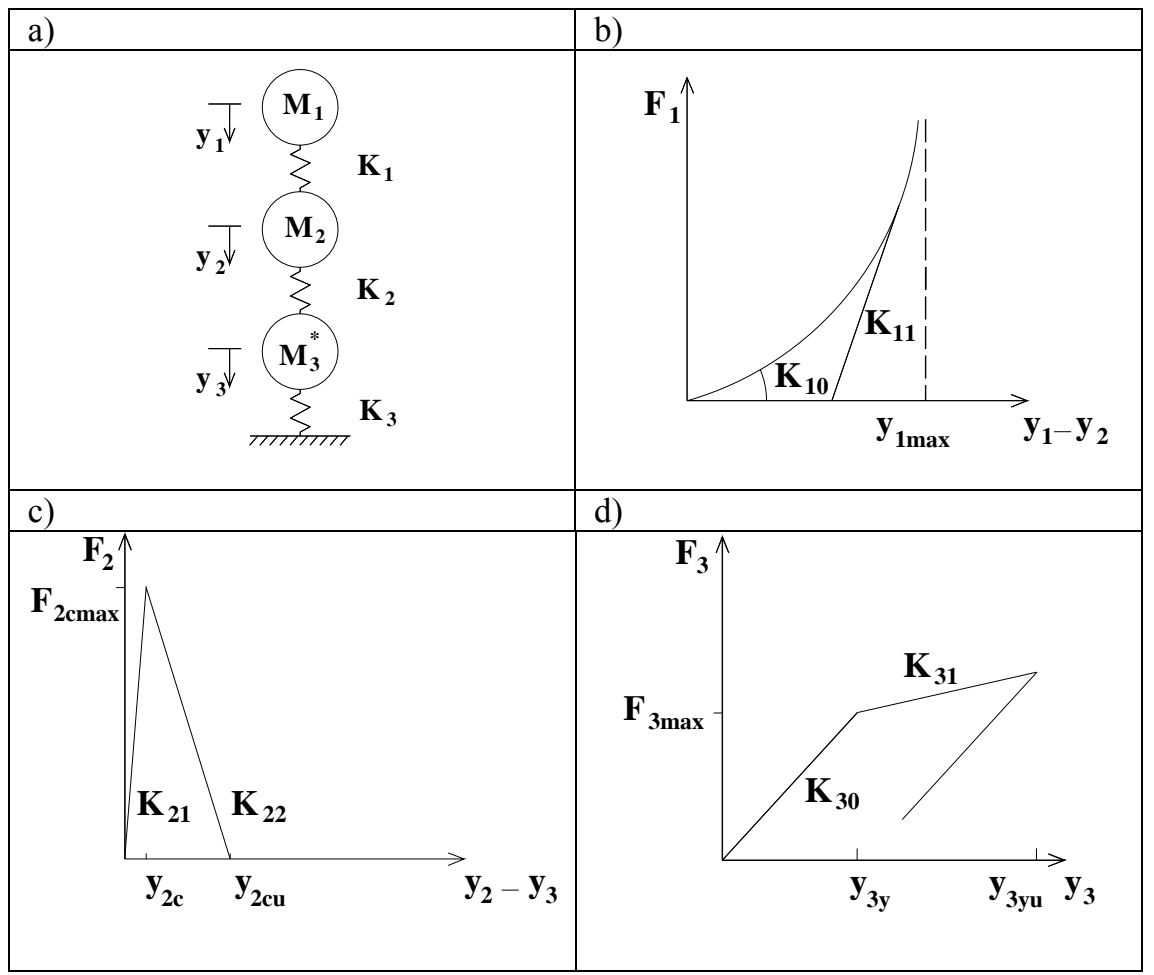

Figure 5: Analytical model: a) system of three degrees of freedom, properties of b) cushion, c) punching cone d) global response.

With regard to the dynamic impact load capacity of the reinforced concrete slabs, bending and shear forces must be considered as depending on each other. Thus for the evaluation of the impact forces, an analytical model consisting of a system of multiple degrees of freedom is proposed. It consists of three masses with the corresponding nonlinear springs as shown in Figure 5. 


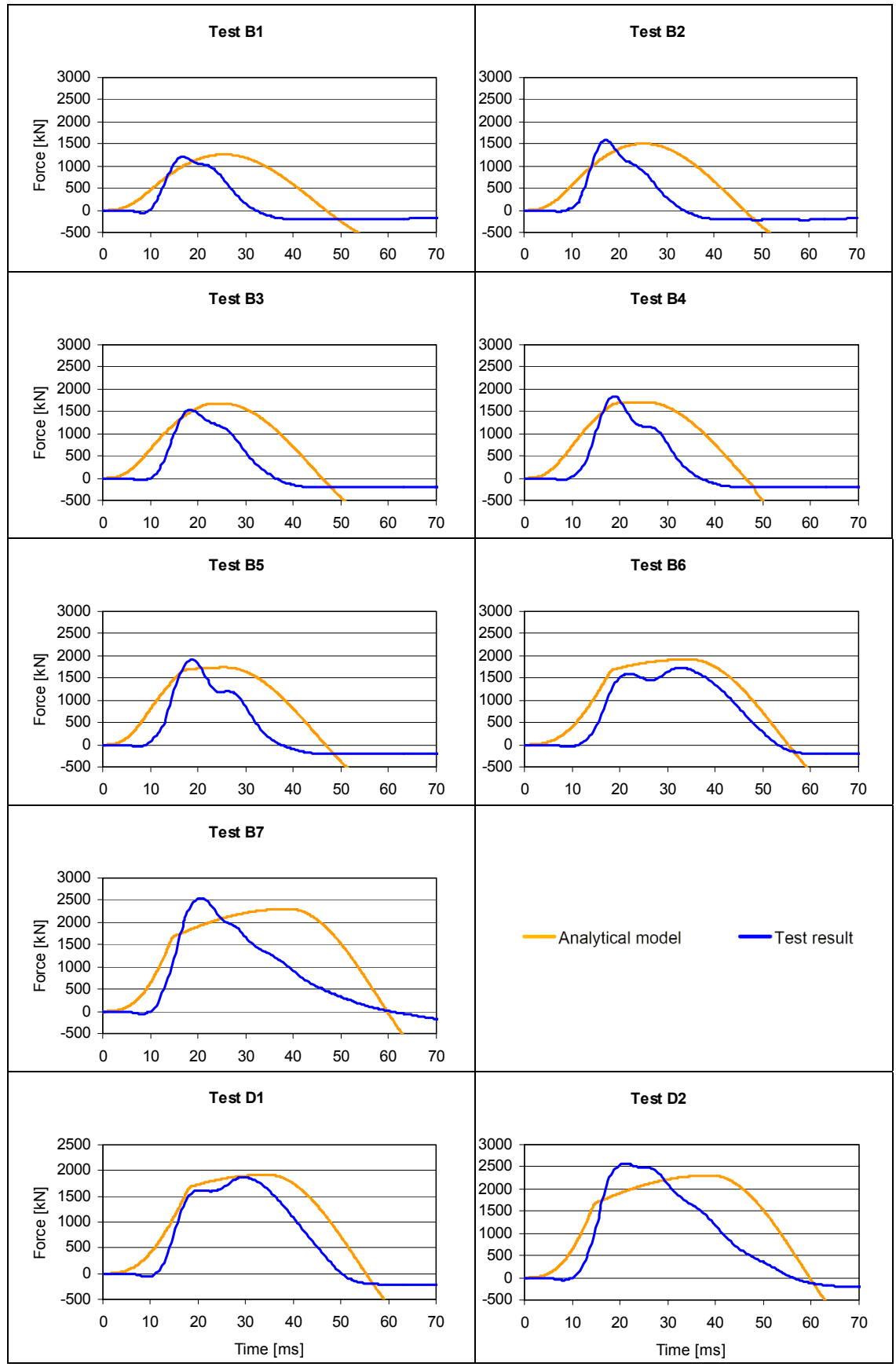

Figure 6: Comparison of force time history from tests and analytical model. 
For the application, the adequate selection of the different masses and appropriate values of the spring stiffnesses is required. The first mass $M_{1}$ is the impacting boulder. $M_{2}$ corresponds to an assumed punching cone and $M_{3}{ }^{*}$ is the effective vibrating mass for the rest of the structure, which governs the global behaviour of the gallery. $K_{1}$ describes the properties of the cushion layer, $K_{2}$ describes the shear behaviour of the assumed critical section and $K_{3}$ describes the bending stiffness of the global system.

For the described tests, the masses and the spring properties have been selected as follows:

- $\quad M_{1}$ according to the falling weights given in Table 1 (800 or $4000 \mathrm{~kg}$ )

- $M_{2}: 1720$ or $2880 \mathrm{~kg}$ for the 800 or $4000 \mathrm{~kg}$ boulder, respectively

- $M_{3}{ }^{*}: 10030$ or $9320 \mathrm{~kg}$ for the 800 or $4000 \mathrm{~kg}$ boulder, respectively

- $K_{10}$ : according to the $M_{E}$-value given in Table 1

- $K_{11}$ : maximum $M_{E}$-value reached before unloading, following Equation (1):

$$
K_{11}=K_{10} \cdot\left(\frac{1}{1-\frac{y_{1}-y_{2}}{y_{1 \max }}}\right) \text { and } y_{1 \max }=0.2 \mathrm{~m}
$$

- $K_{21}: 156000000 \mathrm{kN} / \mathrm{m}$

- $K_{30}: 79100 \mathrm{kN} / \mathrm{m}$

- $K_{31}: 11800 \mathrm{kN} / \mathrm{m}$

- $F_{2 c \max }$ : force when relative displacement $y_{2}-y_{3}$ reaches $0.033 \mathrm{~mm}$

- $F_{3 \max }: 1670 \mathrm{kN}$

With these values and the following formulations the resulting force in the spring $K_{3}$ is compared with the test results of B1 to B7 and D1 to D2 (Figure 6). It can be observed, that the peak load can be estimated sufficiently accurate. In general the impact time is slightly overestimated, but in a range that is of minor importance for the design.

Once the input parameters are calculated, the proposed analytical model can easily be solved in a negligible calculation time by a calculation sheet or using a simple finite element program.

\section{Comparison with design guidelines}

The Swiss and the Japanese design guidelines for rock fall impacts on protective structures are presented for reason of comparison.

In the Swiss guideline of the Road Administration (ASTRA) and the Federal Railways (SBB) published in 1998, the static equivalent load is given by Equation (2) and based on impact tests carried out in 1996. The tests focused on the influence of the soil cushion layer [6]. The tests were performed in an energy range of about $100 \mathrm{~kJ}$ and extrapolated using finite element simulations [7]. Recently the guideline was adapted to the new generation of design codes of 2003 without any changes regarding the technical content. 


$$
F=2.8 \cdot e^{-0.5} \cdot R^{0.7} \cdot M_{E}^{0.4} \cdot \tan \varphi \cdot\left(\frac{m \cdot v^{2}}{2}\right)^{0.6}
$$

where $F$ is static equivalent force, $e$ is the thickness of the cover layer, $v$ is the impact velocity, $R$ is the radius of an equivalent sphere, $m$ is boulder mass, $\varphi$ is the internal friction angle of cushion material and $M_{E}$ is the soil modulus of the cushion layer.

Besides numerous documents with recommendations for the design of rock fall impacts on structures, the manual for anti-impact structures against falling rocks published in 1983 by the Japan Road Association [8] is the most significant document. The impact load is given by Equation (3) and based on the Hertzian contact theory.

$$
P=2.108(m \cdot g)^{\frac{2}{3}} \cdot \lambda^{\frac{2}{5}} \cdot H^{\frac{3}{5}} \cdot \alpha
$$

where $P$ is static equivalent force $[\mathrm{kN}], \lambda$ is the lame constant $\left[\mathrm{kN} / \mathrm{m}^{2}\right], g$ is the acceleration of gravity $\left[\mathrm{m} / \mathrm{s}^{2}\right], H$ is the falling height $[\mathrm{m}], m$ is the boulder mass [t] and $\alpha$ is the internal friction angle of cushion material.

Figure 7 shows the agreement of the results of the analytical model, the impact reaction forces from the tests, and the design loads of the two guidelines. The latter are conservative in this higher range of impact energies for this selected setup.

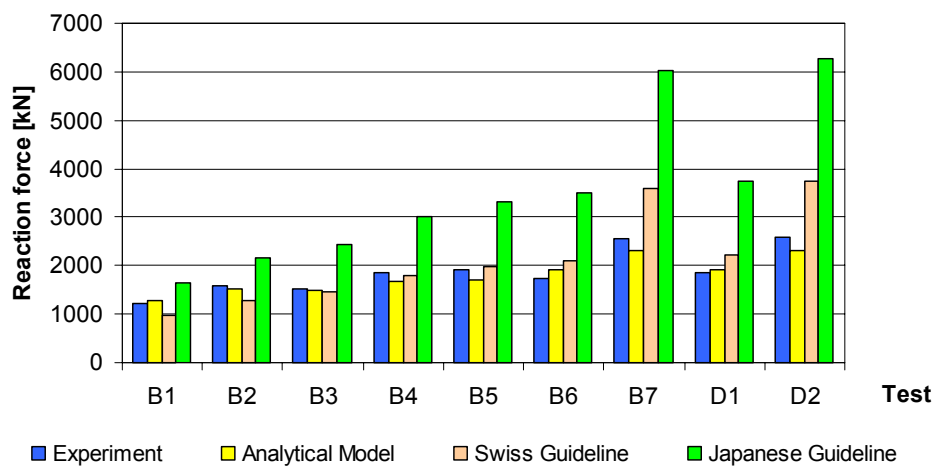

Figure 7: Comparison test results, design loads from guidelines and model.

\section{Conclusions}

The dynamic response of the structure is expected to considerably influence the bending moments and the local shear forces that are relevant for the design. The proposed analytical model can predict the reaction forces of rock fall impacts on protection galleries.

Analyzing the crack patterns has provided an overview of the slab behavior subjected to impact. Although the slabs had ultimately failed in a combined shear-flexure mechanism, the crack patterns of the first impacts are controlled by orthogonal cracking. 
A reveres prediction of the impact loads from the crack patterns or crack spacing is difficult as cracking is influenced by several factors like the rebar spacing for instance. The previous impacts in the history affect the crack spacing as well.

\section{Outlook and acknowledgements}

Combination of computational and experimental results leads to a better understanding of structural behaviour. Numerical simulation of these large scale field tests is planned next. The results of finite element simulations calibrated with field experiments will enable a reasonable extension of the test results. The predictions of the impact loads by a relatively simple model will help to easily analyze a larger amount of design situations and will help to improve the new guideline generations.

We would like to express our sincere thanks to Dr. A. Volkwein (WSL) and A. Roth (Geobrugg Protection Systems, Switzerland) for the productive cooperation during the experiments. Special thanks are also addressed to the highway administrations of the cantons of Grison and Uri for their indispensable financial support.

\section{References}

[1] ASTRA, SBB (1998). Einwirkungen auf Steinschlagschutzgalerien, Richtlinie, Bundesamt für Strassen, Baudirektion SBB, Bern, 1998.

[2] Schellenberg, K., Volkwein, A., Roth, A., Vogel, T. (2007). Large-scale impact tests on rock fall galleries, 7th International Conference on Shock \& Impact Loads on Structures, 17-19 October 2007, Beijing, pp. 497-504.

[3] Zorn Stendal (1996), Operating Manual, Light Drop-Weight Tester ZFG02, Germany.

[4] Marti, P., Alvarez, M., Kaufmann, W., and Sigrist, V., Tension Chord Model for Structural Concrete, Structural Engineering International, International Association for Bridge and Structural Engineering, IABSE, V. 8, No. 4, Nov. 1998, pp. 287-298.

[5] Schellenberg, K., Vogel, T., (2007). Tests and analytical model of rockfall impacts on galleries. Proceedings of Protect2007, Structures under Extreme Loading, Aug. 20-22, Whistler, p. 27.

[6] Montani, S. (1998). Sollicitation dynamique de la couverture des galleries de protection lors de chutes de blocs, Dissertation, Nr. 1899, École Polytechnique Fédérale de Lausanne, 190 pp.

[7] Bucher, K. (1997). Dynamische Berechnung von Steinschlageinwirkungen, Proceedings, Schweizerische Gesellschaft für Boden und Felsmechanik, Conference Paper Montreux.

[8] Japan Road Association (1983). Manual for anti-impact structures against falling rocks (in Japanese). 